\title{
Wavelet transform of heart rate variability to assess autonomic nervous system activity does not pre- dict arousal from general anesthesia
}

[La transformée par ondelettes de la variabilité de la fréquence cardiaque, utilisée pour évaluer l'activité du SNA, ne permet pas de prédire le moment du réveil après l'anesthésie générale]

Vincent Pichot PhD, ${ }^{*}$ Sabine Buffière MD, $†$ Jean-Michel Gaspoz MD MSc, $\ddagger$ Frederic Costes MD, ${ }^{*}$ Serge Molliex MD PhD, $\dagger$ David Duverney BS, ${ }^{*}$ Frederic Roche MD, ${ }^{*}$ Jean-Claude Barthélémy MD PhD*

Purpose: The relationship between autonomic nervous system (ANS) activity and general anesthesia has been explored. Studies have demonstrated partial recovery of heart rate variability (HRV), representative of ANS activity, in the postoperative period, but the arousal period has not been precisely studied. The goals of this study were to analyze modifications of ANS activity during general anesthesia and, more particularly, around the arousal period, to look for predictors of arousal.

Methods: We analyzed HRV changes using wavelet transform, a time-frequency analysis that, in contrast to Fourier transform, is able to assess abrupt changes of ANS activity. Seventeen patients (mean \pm SD age: $40.9 \pm 16.4 \mathrm{yr}$ ) under general anesthesia for hip or knee surgery, were included in the study. The analysis began one hour before anesthesia, focussed on eye opening, and ended three hours after arousal.

Results: There was a dramatic decrease in HRV after induction, that extended throughout anesthesia and represented a decrease in global autonomic regulation with, however, a relative predominance of vagal tone. At the moment of eye opening, there was an abrupt change in HRV, representing a sudden shift of ANS balance towards the predominance of sympathetic activity, while none of these indices changed seconds before arousal.

Conclusions: Wavelet analysis of HRV appears to be powerful tool to precisely assess instantaneous changes of HRV during anesthesia. Using this method, there were no identifiable precursory $H R V$ indices of arousal.
Objectif : On connaît la relation entre l'activité du système nerveux autonome (SNA) et l'anesthésie générale. Des études ont démontré la récupération postopératoire partielle de la variabilité de la fréquence cardiaque (VFC), représentant l'activité du SNA, mais le retour à la conscience n'a pas été précisément étudié. Les objectifs de la présente étude sont d'analyser les modifications de l'activité du SNA pendant l'anesthésie générale et, plus particulièrement, la période entourant le retour à la conscience, afin de découvrir des prédicteurs de réveil.

Méthode : Nous avons analysé les changements de VFC en utilisant la transformée par ondelettes, une analyse temps-fréquence qui, contrairement à la transformée de Fourier, permet d'évaluer les changements brusques de l'activité du SNA. Dix-sept patients (âge moyen \pm écart type: 40,9 \pm 16,4 ans), sous anesthésie générale pour une intervention à la hanche ou au genou, ont participé à l'étude. L'analyse, centrée sur l'ouverture des yeux, a débuté une heure avant l'anesthésie et s'est terminée trois heures après le retour à la conscience.

Résultats : Après l'induction de l'anesthésie, il s'est produit une baisse marquée de la VFC qui s'est prolongée tout au long de l'anesthésie et qui représentait une diminution de la régulation autonome globale accompagnée, toutefois, d'une relative prédominance du tonus vagal. À l'ouverture des yeux, il y a eu un changement brusque de la VFC, indice d'un décalage soudain dans l'équilibre du SNA vers une prédominance de l'activité sympathique, alors qu'aucun de ces indices n'avait changé quelques secondes avant le réveil.

Conclusion : L'analyse par ondelettes de la VFC s'est révélée un outil puissant pour évaluer de façon précise les modifications de la VFC pendant l'anesthésie. Cette méthode n'a pas montré d'indices précurseurs identifiables de VFC de réveil.

From the Laboratoire de Physiologie, ${ }^{*}$ Université de Saint-Etienne, Département d'Anesthésie et Réanimation, $†$ Hôpital Universitaire, Saint-Etienne, France; and the Département de Médecine Interne, $\ddagger$ Hopitaux Universitaires de Genève, Switzerland. Address correspondence to: Dr. Jean-Claude Barthélémy, Laboratoire de Physiologie, CHU Nord - Niveau 6, F- 42055 Saint-Etienne, Cedex 2, France. Phone: +33 4778283 00; Fax: +33 4778284 47; Email: JC.Barthelemy@univ-st-etienne.fr

Department in which the study was carried out: Laboratoire de Physiologie, Université de Saint-Etienne, France. Accepted for publication January 9, 2001.

Revision accepted May 25, 2001. 
$\mathrm{H}$

EART rate variability (HRV) analysis is a well recognized tool to assess autonomic nervous system (ANS) activity. In the field of anesthesia, main changes in HRV consist in a decrease beginning at the onset of induction $^{1}$ and persisting throughout anesthesia, followed by a progressive recovery during the hours following arousal ${ }^{2,3}$ that, however, can last up to six days after surgery. ${ }^{4}$

Wavelet transform of HRV allows to precisely assess abrupt changes in ANS activity and balance ${ }^{5}$ triggered by different procedures during surgery under general anesthesia.

The goals of this work were to analyze ANS changes throughout anesthesia, focussing on the arousal period, to determine if HRV could be used as a precursory index of arousal.

\section{Material and methods}

Subjects

Seventeen patients (mean \pm SD age: $40.9 \pm 16.4 \mathrm{yr}$ ) undergoing hip or knee arthroplasty were included in the study. None had any disease influencing HRV nor were on cardiac medication. The study was approved by the Ethics Commitee of the University Hospital of Saint-Etienne, France, and all subjects signed an inform consent.

Protocol

All patients received $100 \mathrm{mg}$ hydroxyzine one hour before anesthesia; induction was performed with midazolam $\left(10 \mathrm{~g} \cdot \mathrm{kg}^{-1}\right)$, fentanyl $\left(4 \mathrm{~g} \cdot \mathrm{kg}^{-1}\right)$, atracurium $\left(0.5 \mathrm{mg} \cdot \mathrm{kg}^{-1}\right)$ and propofol $\left(2 \mathrm{mg} \cdot \mathrm{kg}^{-1}\right)$, followed by endotracheal intubation. Ventilation was controlled at a rate of ten cycles per minute, with a tidal volume of $10 \mathrm{~mL} \cdot \mathrm{kg}^{-1}$. Narcosis was maintained with isoflurane and $\mathrm{NO}_{2}$, supplemented by iv fentanyl and atracurium, if needed. Administration of isoflurane and $\mathrm{NO}_{2}$ was stopped at the end of skin suture; then, patients were moved to the recovery room for one to three hours. There, they were extubated just after arousal, i.e., after eye opening.

A continuous electrocardiograpic (ECG) recording was performed using Holter monitoring, beginning one hour before induction and ending three hours after arousal.

\section{HRV analysis}

We extracted $\mathrm{R}$ wave-to- $\mathrm{R}$ wave intervals from an ECG Holter system (StrataScan 563, Del Mar, Irvine CA, USA) with a sampling frequency of $128 \mathrm{~Hz}$. Resulting RR signals were re-sampled at $2 \mathrm{~Hz}$ using a cubic spline interpolation. Then, wavelet transform was performed to obtain the evolution of the power of the signal at different levels (frequencies) of decomposition, which allowed to calculate the temporal evolution of standard ANS indices Ptot=total power; $\mathrm{VLF}=$ very low frequency $(0.00-0.04 \mathrm{~Hz} ; \mathrm{LF}=$ low frequency $(0.04-0.015 \mathrm{~Hz}) ; \mathrm{HF}=$ high frequency $(0.15-0.40 \mathrm{~Hz})$; LFnu and HFnu=LF and HF expressed in normalized units (their power spectrum over Ptot-VLF, \%), as previously described. 5,6

On the whole, it is commonly assumed that HF and HFnu represent parasympathetic activity and that LF and LFnu represent both parasympathetic and sympathetic activities. Autonomic balance is calculated as the $\mathrm{LF} / \mathrm{HF}$ ratio. Ptot represents global activity of the ANS and VLF also contains parasympathetic activity.

We averaged HRV indices over periods of ten minutes for the following phases: immediately before induction; immediately after intubation; immediately before and immediately after eye opening; one and two hours after arousal. In addition, we focussed on the arousal period by averaging indices over oneminute intervals, for ten minutes before to ten minutes after eye opening, as well as from 20 and $30 \mathrm{~min}$ before to 60 and $120 \mathrm{~min}$ after eye opening.

\section{Statistical analysis}

Wavelet analysis, graphics and statistics were conducted with the softwares MatLab and Statview, on a PowerMacintosh. A two-factor analysis of variance with Scheffe post hoc was performed with patients and times. Only results with $P<0.05$ were considered significant.

\section{Results}

Endotracheal isoflurane concentration was $1.1 \pm 0.2 \%$ $($ mean $\pm \mathrm{SD})$ and fentanyl doses were $2.45 \pm 0.70$ $\cdot \mathrm{kg}^{-1} \cdot \mathrm{hr}^{-1}($ mean $\pm \mathrm{SD})$. None of the patients required atropine or phenylephrine injections, or other drugs that could modify cardiovascular or ANS status.

Induction and intubation (Table and Figure 1)

Induction and intubation resulted in an overall profound decrease in autonomic outflow, while autonomic equilibrium shifted towards predominance of the parasympathetic arm during anesthesia.

Eye opening (Figures 1 and 2)

Eye opening was associated with sudden changes in HRV indices: there was a dramatic decrease in mean $\mathrm{RR}$ intervals and a shift of the autonomic balance towards predominance of the sympathetic arm. There were no significant variations in HRV indices before eye opening. 
TABLE Evolution of heart rate variability during anesthesia

\begin{tabular}{lllllll}
\hline & $\begin{array}{l}\text { B-Ind } \\
\text { Mean } \pm S D\end{array}$ & $\begin{array}{l}\text { A-Int } \\
\text { Mean } \pm S D\end{array}$ & $\begin{array}{l}\text { B-EO } \\
\text { Mean } \pm S D\end{array}$ & $\begin{array}{l}A \text {-EO } \\
\text { Mean } \pm S D\end{array}$ & $\begin{array}{l}\text { EO+60 } \\
\text { Mean } \pm S D\end{array}$ & $\begin{array}{l}\text { EO+120 } \\
\text { Mean } \pm S D\end{array}$ \\
\hline RR $(\mathrm{ms})$ & $921 \pm 201$ & $1070 \pm 214$ & $969 \pm 213$ & $736 \pm 200$ & $856 \pm 198$ & $854 \pm 155$ \\
Ptot $\left(s^{2}\right)$ & $0.742 \pm 1.190$ & $0.539 \pm 1.559$ & $0.646 \pm 1.263$ & $1.271 \pm 1.976$ & $0.496 \pm 0.754$ & $0.947 \pm 3.594$ \\
VLF $\left(s^{2}\right)$ & $0.701 \pm 1.161$ & $0.532 \pm 1.557$ & $0.638 \pm 1.260$ & $1.258 \pm 1.969$ & $0.464 \pm 0.732$ & $0.918 \pm 3.586$ \\
LF $\left(s^{2}\right)$ & $0.034 \pm 0.052$ & $0.006 \pm 0.012$ & $0.006 \pm 0.010$ & $0.012 \pm 0.014$ & $0.026 \pm 0.032$ & $0.026 \pm 0.030$ \\
HF $\left(s^{2}\right)$ & $0.007 \pm 0.010$ & $0.002 \pm 0.002$ & $0.002 \pm 0.003$ & $0.002 \pm 0.003$ & $0.006 \pm 0.009$ & $0.004 \pm 0.006$ \\
LF/HF & $95.6 \pm 185.8$ & $65.9 \pm 245.8$ & $54.4 \pm 144.2$ & $164.6 \pm 297.0$ & $69.5 \pm 114.5$ & $78.3 \pm 150.6$ \\
LFnu (\%) & $74.8 \pm 17.5$ & $68.2 \pm 16.7$ & $67.2 \pm 18.8$ & $81.5 \pm 13.5$ & $76.4 \pm 13.7$ & $75.9 \pm 14.4$ \\
HFnu (\%) & $25.2 \pm 17.5$ & $31.8 \pm 16.7$ & $32.8 \pm 18.8$ & $18.5 \pm 13.5$ & $23.6 \pm 13.7$ & $24.1 \pm 14.4$ \\
\hline
\end{tabular}

B-Ind=before induction; A-Int=after intubation; B-EO=before eye opening; A-EO=after eye opening; EO+60=60 min after eye opening; $\mathrm{EO}+60=120 \mathrm{~min}$ after eye opening.

$\mathrm{RR}=$ all significantly different $(P<0.001)$, except $\mathrm{EO}+60 v s \mathrm{EO}+120$. Ptot, VLF=A-Int $v s \mathrm{~A}-\mathrm{EO}(P<0.01)$; B-EO $v s \mathrm{~A}-\mathrm{EO}(P<0.05)$; A-EO $v s$ $\mathrm{EO}+60(P<0.001) . \mathrm{LF}=$ all significantly different $(P<0.001)$, except B-Ind $v s \mathrm{EO}+60$ and $\mathrm{EO}+120$; A-Int $v s \mathrm{~B}-\mathrm{EO}$ and A-EO; B-EO $v s \mathrm{~A}-\mathrm{EO}$ $\mathrm{EO}+60$ vs $\mathrm{EO}+120 . \mathrm{HF}=$ all significantly different $(P<0.001)$, except A-Int $v s \mathrm{~B}-\mathrm{EO}$ and A-EO; B-EO $v s \mathrm{~A}-\mathrm{EO}$. LF/HF: A-EO $v s \mathrm{~A}-\mathrm{Int}$ and B$\mathrm{EO}$ and EO+60 $(P<0.001)$; A-EO $v s \mathrm{~B}-\mathrm{Ind}(P<0.05)$; A-EO $v s \mathrm{EO}+120(P<0.01)$. LFnu, HFnu=all significantly different $(P<0.001)$, except $\mathrm{B}-$ Ind $v s \mathrm{EO}+60$ and $\mathrm{EO}+120 ; \mathrm{A}$-Int $v s \mathrm{~B}-\mathrm{EO} ; \mathrm{EO}+60$ vs $\mathrm{EO}+120$

Postoperative period (Table and Figure 1)

ANS showed a progressive increase of both arms, parasympathetic and sympathetic with, however, a progressive increase of parasympathetic activity, reaching the same equilibrium as before induction at 60 min postarousal, while global HRV remained lower in absolute values.

\section{Discussion}

Using wavelet transform of HRV recorded during anesthesia, our study showed a dramatic decrease in Ptot with a shift of the autonomic nervous activity toward predominance of the parasympathetic arm. This reflected the resting bradycardia induced by propofol anesthesia and the combined effects of the different drugs administered to the patients. ${ }^{7}$ At the time of arousal, there was an abrupt shift of the ANS towards predominance of the sympathetic arm. However, HRV analysis could not provide precursory indices of eye opening.

Of note, the high frequencies of HRV, which are recognized indices of the vagal modulation of respiration, remained greatly depressed, even when spontaneous respiration resumed. This prolonged impairment of autonomic function after arousal might be useful as an index of the quality of recovery.

Time-frequency wavelet analysis of HRV is an effective tool to get instantaneous representations of HRV and to accurately detect sudden shifts in ANS activity and balance. ${ }^{5,6}$ Thus, it is particularly well suited to assess changes in HRV occuring during induction, surgical procedures, drug administration, ventilation mode and recovery. In practice, such an analysis is easily programmable for on-line monitoring. Thus, time-frequency analysis of the variability of heart rate and blood pressure could be added to usual monitors of blood pressure, heart rate or bispectral index. Such sophisticated analyses could help anesthesiologists understand better the impact of drugs they administer on the regulation of the ANS by the central nervous system.

\section{References}

1 Huang $H-H$, Chan H-L, Lin P-L, Wu C-P, Huang C$H$. Time-frequency spectral analysis of heart rate variability during induction of general anaesthesia. $\mathrm{Br} \mathrm{J}$ Anaesth 1997; 79: 754-8.

2 Donchin $\Upsilon$, Feld $M F$, Porges $S W$. Respiratory sinus arrhythmia during recovery from isoflurane-nitrous oxide anesthesia. Anesth Analg 1985; 82: 113-8.

3 Fleisher LA, Franck SM, Shir Y, Estafanous M, Kelly S, Raja $S N$. Cardiac sympathovagal balance and periferal sympathetic vasoconstriction: epidural versus general anesthesia. Anesth Analg 1994; 79: 165-71.

4 Marsch SCU, Skarvan K, Schaefer HG, et al. Prolonged decrease in heart rate variability after elective hip arthroplasty. Br J Anaesth 1994; 72: 643-9.

5 Pichot V, Gaspoz J-M, Molliex S, et al. Wavelet transform to quantify heart rate variability and to assess its instantaneous changes. J Appl Physiol 1999; 86: 1081-91.

6 Task force of the European Society of Cardiology and the North American Society of Pacing and Electrophysiology. Heart rate variability. Standards of Measurement, physiological interpretation, and clinical use. Circulation 1996; 93: 1043-65.

7 Deutschman CS, Harris AP, Fleisher LA. Changes in heart rate variability under propofol anesthesia: a possible explanation for propofol-induced bradycardia. Anesth Analg 1994; 79: 373-7.

8 Brubn J. EEG indices and heart rate variability as measures of depth of anaesthesia (Letter). Br J Anaesth 1999; 83: 687 

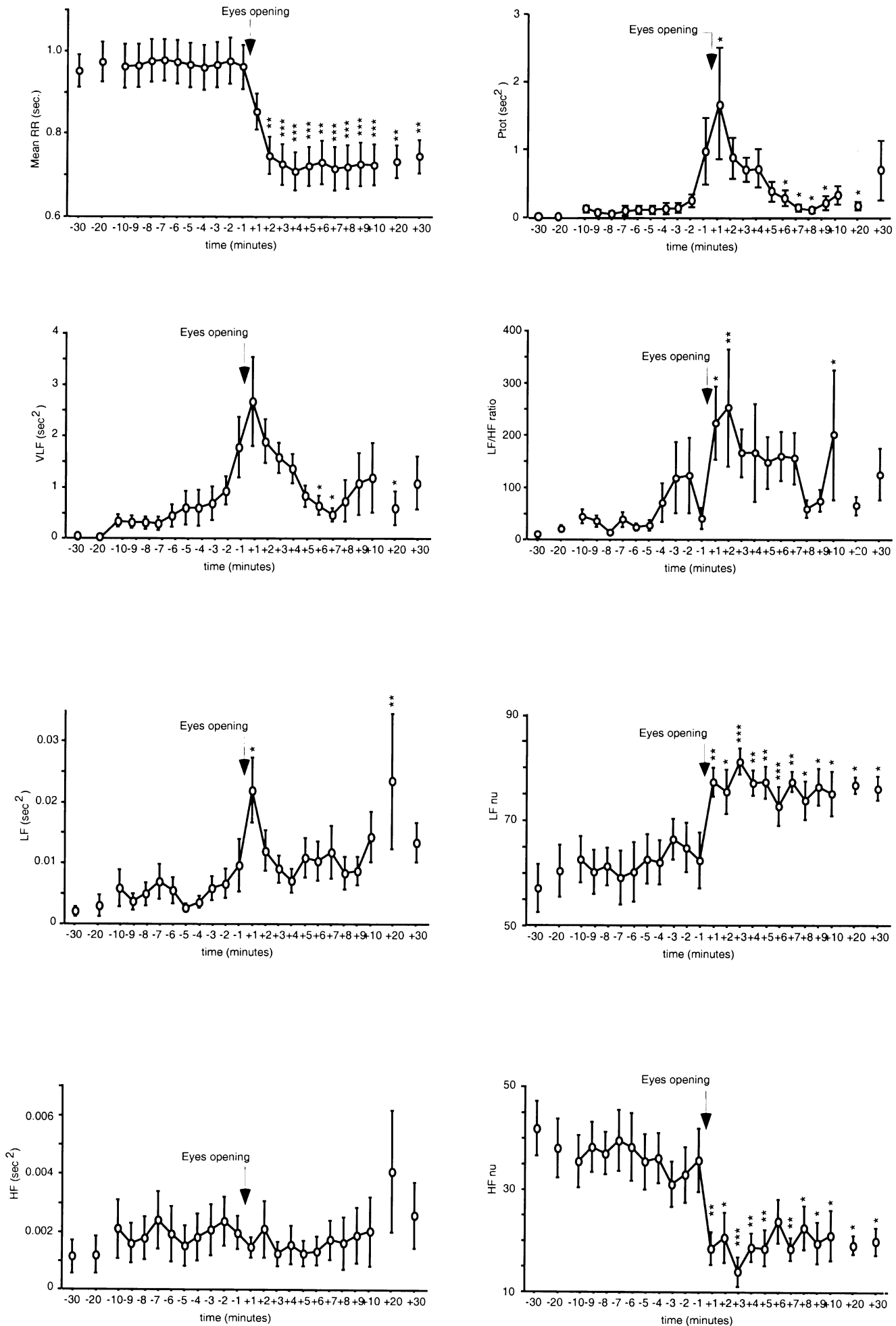

FIGURE 1 Autonomic nervous system indices obtained from wavelet analysis for the 17 patients, averaged on one- minute intervals and plotted minute by minute from $-10 \mathrm{~min}$ to $+10 \mathrm{~min}$ around eye opening time, as well as at 30 and $20 \mathrm{~min}$ before and after eye opening. ${ }^{*} P<0.05$, ${ }^{* *} P$ $<0.01, * * * P<0.001, \mathrm{NS}=$ not significant. 

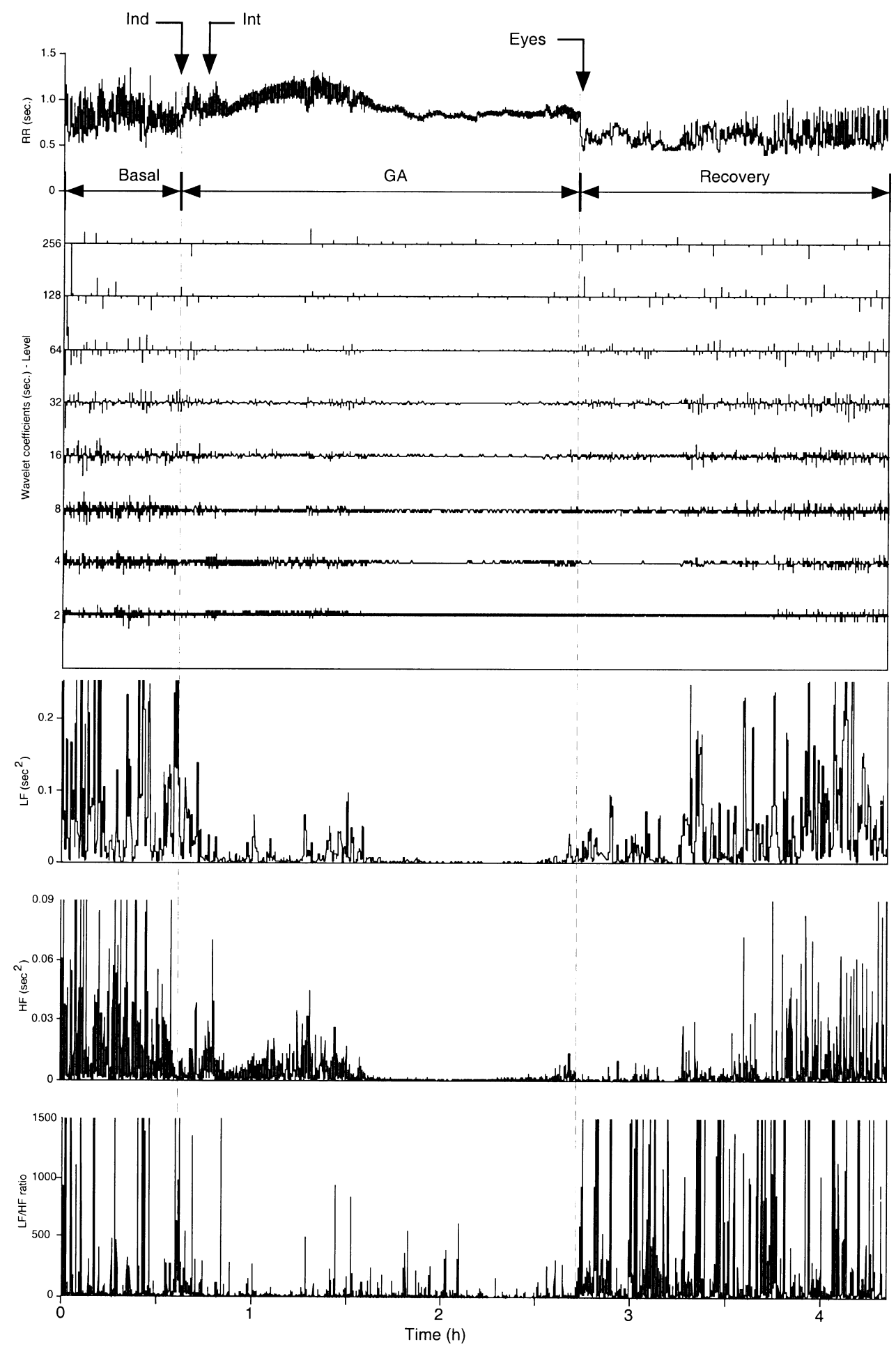

FIGURE 2 Example of wavelet analysis of heart rate variability (HRV) of a patient from the pre-induction period to two hours postanesthesia. The top of the figure represents HRV plotted against time. The middle panel shows corresponding wavelet coefficients. The last three panels are the evolution of LF, HF and LF/HF ratio respectively, obtained from wavelet analysis. Each graphic is plotted against the same time base. The following abbreviations are used to indicate the states and events: Basal, for the pre-induction period; GA, for general anesthesia; Recovery, for the period following arousal; Ind, for induction; Int for intubation; and Eyes, for eye opening time. 